\title{
El Congreso médico-regional de Navarra (1886): un ejemplo de la transmisión del conocimiento científico
}

\author{
The "Regional-Medical Congress of Navarre" (1886): \\ an exercise in sharing scientific knowledge
}

\author{
P. León
}

\section{RESUMEN}

La última ola epidémica del cólera en Navarra (1884-1885) es la menos estudiada porque apenas afectó a Pamplona, el núcleo urbano más importante de la región, pero creó una situación crítica en otras áreas como la Ribera.

Fundamento. El "Congreso médico-regional de Navarra" celebrado en Tafalla (Navarra), en 1886, se convocó para estudiar la epidemia de cólera de 1885 en la región. El interés de esta reunión científica estriba en la actitud de los médicos ante el desarrollo de la microbiología y la higiene pública. En un momento en que Robert Koch aisla el Bacillus vírgula, en 1883, y tiene lugar la polémica desarrollada por la difusión de la vacuna de Jaime Ferrán y Clúa, en 1885.

Material y métodos. A través de las actas y de las memorias presentadas al Congreso analizamos la influencia de autores e instituciones internacionales en los profesionales navarros.

Conclusiones. La reunión científico médica de Tafalla fue una iniciativa singular para Navarra. En ella se observa la transferencia de ideas de los congresos internacionales sobre la epidemia colérica. Esta influencia fue mediada por personalidades como Nicasio Landa y A. Espina y Capo. Hemos observado diferencias en las concepciones de los médicos, en el momento en el que no existía una teoría etiopatogénica única. La metodología seguida por los médicos ejemplifica el análisis y las medidas higiénico sanitarias propuestas para combatir el cólera.

Palabras clave. Epidemia de cólera 1885. Navarra. Historia de la práctica profesional. Congresos CientíficoMédicos. Siglo XIX.

\begin{abstract}
This paper discusses the last wave of cholera in Navarre (1884-85). This epidemic has been the least studied because it barely affected Pamplona, the largest urban area in the province. But the situation was critical in other zones close to the River Ebro (the Ribera area).

Background. In 1886, the "Regional-Medical Congress of Navarre", held in Tafalla (Navarre), studied the latest cholera epidemic in the region. An analysis of this scientific meeting is of interest because of the data it offers on the physicians' reactions to the development of microbiology and public hygiene, shortly after Robert Koch had isolated the comma-shaped cholera bacillus in 1883 ("Bacillus virgula"), and the controversy over the distribution of the vaccine by Jaime Ferrán y Clúa, in 1885 .
\end{abstract}

Material and methods. Analysis of the conference reports presented at the "Regional-Medical Congress".

Conclusions. This scientific medical gathering in Tafalla was innovative for Navarre. The transfer of ideas from international conferences on the cholera epidemic can be seen. The development of the Conference was influenced by medical celebrities like Nicasio Landa and Antonio Espina y Capo. We can also observe differences in the physicians' ideas. At the time there was no paradigm on microbiology in the world of science. The questionnaires produced by the Navarrese physicians for the study of the epidemic are a good example of the procedure for analysing a public health problem and of the measures proposed in a situation of cholera epidemic.

Key words. Cholera epidemics of 1885 . Navarre. Professional practice/history. Professional Meetings and Conferences. 19th Century History.

\section{An. Sist. Sanit. Navar. 2009; 32 (2): 149-159}

Facultad de Medicina. Universidad de Navarra.

$$
\text { Pamplona. }
$$

Un resumen de este trabajo fue presentado en el International Seminar "The Creation of Scientific Information Networks. Scientific information exchange among professionals working in the area of health sciences during the second half of the 19th century", Palma de Mallorca, 29-31 Mayo, 2008.

Recepción: 10 de febrero de 2009

Aceptación provisional: 18 de marzo de 2009

Aceptación definitiva: 27 de abril de 2009

\author{
Correspondencia \\ Pilar León Sanz \\ Profesora de Historia de la Medicina \\ Departamento de Humanidades Biomédicas \\ Facultad de Medicina. Universidad de Navarra \\ Irunlarrea $\mathbf{s} / \mathbf{n}$ \\ 31008 Pamplona \\ E-mail:mpleon@unav.es
}




\section{INTRODUCCIÓN}

Durante el siglo XIX se produjeron en Europa varias ondas epidémicas de cólera. Aquí vamos a referirnos a la quinta de estas epidemias que se inició en Francia, en junio de 1884, procedente de Egipto y se extinguió en 1885. La invasión afectó a Francia, Italia y España.

A España llegó en septiembre de 1884 y se manifestó en focos aislados en Alicante, Valencia, Gerona, Barcelona y Toledo. Las bajas temperaturas del invierno hicieron que la infección permaneciera acantonada en las provincias de Alicante y Valencia. En marzo de 1885 reapareció en Játiva (Valencia) y desde allí se extendió a toda la península, hasta que el 31 de diciembre de 1885 , se dio por finalizada la epidemia en el país ${ }^{1}$.

De forma global, el número de invadidos en España fue de 339.794, de los que fallecieron 120.245. Los focos más importantes de la epidemia, además de Levante, se situaron en Zaragoza y Granada. En Zaragoza se dio el máximo de fallecidos/día $(95,25)$ y el mayor porcentaje de invadidos respecto a la población sometida a la epidemia $(15,7 \%)^{2}$.

Por ser Navarra una región limítrofe con Aragón, se explica el paso de la epidemia a la zona geográficamente unida a Zaragoza por la cuenca del río Ebro (Partido Judicial de Tudela). En Navarra, esta ola epidémica ha sido la menos estudiada, probablemente porque apenas afectó a Pamplona, capital y núcleo urbano más importante de la región. Sin embargo, el cólera de 1885 creó una situación crítica en la zona denominada la Ribera, como lo demuestra las repercusiónes demográficas de la epidemia en esta zona ${ }^{3-6}$.

En este artículo pretendemos observar la transmisión de los avances científicos entre los profesionales a través del congreso médico-regional reunido en Tafalla (Navarra), en 1886, al término de la epidemia de cólera. Para ello, en primer lugar revisaremos los objetivos y desarrollo de la reunión científica. A través de las memorias presentadas analizaremos la influencia de autores, instituciones y congresos cientí- ficos internacionales, en los profesionales navarros. Nos centraremos principalmente en el acercamiento estadístico a la epidemia, en las teorías etiopatogénicas de la enfermedad que allí se expusieron y en las propuestas higiénico-sanitarias de ahí derivadas.

\section{MATERIAL Y MÉTODOS}

\section{El Congreso Médico-Regional de Navarra (1886)}

Poco después de que cesara la epidemia, a finales de diciembre de 1885 , los médicos navarros convocaron un congreso para estudiar la epidemia de cólera padecida por la región. Tendría lugar en Tafalla (población cercana a Pamplona), durante los días 22, 23 y 24 de marzo de 1886?

Se ha de subrayar, en primer lugar, la singularidad de la convocatoria, ya que los congresos médicos regionales no eran frecuentes en la España de la época. Resulta significativo el procedimiento seguido por los médicos de Navarra para atender al conocimiento del cólera si lo comparamos, por ejemplo, con lo llevado a cabo en otras ciudades como Zaragoza, donde las autoridades dispusieron el nombramiento de una comisión. En general, el debate científico sobre la etiología y el tratamiento del cólera se desarrolló a través de los informes emitidos por las diversas comisiones nombradas al efecto; los informes de la Sociedad Española de Higiene y de las academias de medicina así como a través de las polémicas en la prensa profesional ${ }^{1}$.

Puede establecerse un paralelismo entre la convocatoria de esta reunión y la de los congresos internacionales habidos hasta el momento, que estuvieron centrados en el estudio de las epidemias de cólera. Es probable que en la organización de la reunión de Tafalla, influyera el médico Nicasio Landa (1830-1891) ${ }^{8}$, uno de los fundadores de la Cruz Roja española y asiduo representante de España en las conferencias médicas internacionales, pues asistió a la Conferencia Internacional de Ginebra (1863), a la de París de 1867 y 1878 , entre otras. 
El congreso médico-regional fue promovido por los profesionales y planteado "sin ayuda alguna oficial y por individual iniciativa", aunque después consiguieron apoyo tanto del Ayuntamiento y de la Diputación de Navarra, como de particulares, como la Sra. Condesa viuda de Guenduláin, que cedió el local en el que se celebraron las reuniones (p. 18).

El congreso reunió sólo a médicos, aunque se trataron algunas cuestiones propias de otro tipo de profesionales como farmacéuticos o arquitectos, cuestión reconocida al inicio de la reunión cuando se hizo constar el agradecimiento de los convocados al Ingeniero de la Diputación, señor Lagarde, por la perfección con que había dirigido el trazado del diagrama de la epidemia (p. 18). Al actuar así, los reunidos están siguiendo la tendencia ya consolidada por los congresos internacionales de higiene de la época.

Según los organizadores, la conferencia pretendía "reunir materiales para hacer la historia fiel de la que acababa de sufrir esta provincia", "contribuir en algo al progreso de la ciencia" y "coordinar las ideas" a través de las experiencias vividas (p. 9). Con perspectiva se ve que los fines del congreso eran dos: unificar criterios de actuación entre los profesionales ante los desacuerdos que se habían suscitado durante los meses anteriores, respecto a las medidas de aislamiento y a los cordones sanitarios; $y$, por otro lado, proponer a la administración municipal y regional algunas reformas sanitarias que se consideraban inaplazables. De ahí el interés por contar en el congreso con los representantes de la Administración.

La convocatoria establecía que dado que una epidemia no es algo individual, sino colectivo, sería necesario "recoger gran número de observaciones, analizarlas y compararlas sistemáticamente" (p. 8). Para ello, junto con la anuncio de la reunión se distribuyó entre los médicos un cuestionario que facilitaba el acopio de los datos de la invasión colérica en cada localidad. Se recibieron 28 memorias con los datos de la evolución del cólera procedentes de
22 localidades (de un total de los 80 ayuntamientos afectados): Azagra, Aibar (2), Larraga, Puente la Reina (2), Mendigorría, Ucar, Caparroso (2), Mélida, Calahorra, Estella, Navarrete (Logroño), Sesma, Larraga; Falces (2), Pamplona (3), Carcastillo, Barasoain, S. Martín de Unx, Miranda de Arga, Tafalla (2), Villafranca, Tudela, Peralta, Murchante, Lerín, Falces, Cintruénigo.

Además, los médicos enviaron otras comunicaciones referidas a un ámbito geográfico más amplio: una sobre el cólera en Navarra, en general, y otra sobre el cólera en Valencia. Y otras memorias con enfoques más teóricos tituladas: "Influencia de las tempestades en el desarrolló del cólera"; "El cólera es infeccioso", "El opio en el tratamiento del cólera", etc.

Los organizadores del congreso fueron, por una parte, el médico de Tafalla, Antonio Martín Ayuso que había obtenido plaza en el Hospital Provincial (1890) y participó activamente en la organización del Colegio de Médicos ${ }^{9}$, y por otra, el médico higienista, Manuel Jimeno y Egúrvide (1856-1937) ${ }^{10}$ que fue inspector Provincial de Sanidad entre 1905-1924. Ambos serían nombrados secretarios de la reunión y actuarían de redactores de las actas y de las conclusiones.

Asistieron un tercio de los médicos navarros: 37 estuvieron presentes en las reuniones y 23 más fueron representados por cuatro médicos. Tan numerosa presencia de médicos hay que situarla en el contexto del intenso movimiento asociacionista médico en la zona, aquél que daría lugar a la creación del Colegio de Médicos Vasco Navarro, en 1898.

Entre los participantes destaca el ya citado Nicasio Landa, que se había significado en la atención a los coléricos en la epidemia de 1855, en Navarra. En aquella onda epidémica había estudiado las características de la enfermedad y había establecido un mapa de morbilidad y mortalidad por provincias que plasmó en la "Memoria sobre la relación que ha existido entre la constitución geológica del terreno y el desarrollo del Cólera-morbo en España”, que presentó a la Real Academia de Medicina de Madrid en $1861^{11}$. En 1885 era miembro de la Junta 
Provincial de Sanidad, desde la que promovió medidas higiénicas para prevenir y limitar la epidemia de cólera ${ }^{12}$. El doctor Landa fue elegido presidente del congreso y, según consta en las actas, presentó una "Memoria sobre la epidemia de 1885 en el Distrito militar de Navarra".

También tomó parte en la reunión el médico y político Antonio Espina y Capo (1850-1930) ${ }^{13,14}$, quien acudió en representación de la Real Academia de Medicina de Madrid y de la prensa profesional de la capital. El doctor Antonio Espina y Capó era médico de la Beneficencia de Madrid. Había publicado numerosos artículos sobre el cólera en la revista Revista de Medicina y Cirugía prácticas (1884-85) y prologó un libro sobre este mismo tema ${ }^{15}$. El doctor Espina fue nombrado presidente honorario y participó muy activamente en los debates que se suscitaron en la reunión de Tafalla.

El representante del Ayuntamiento de Pamplona, Javier Yárnoz, y el de la Diputación de Navarra, Ricardo García, fueron nombrados vicepresidentes del congreso.

Otros médicos que se destacaron por su participación en los debates fueron Manuel Ferrer, Ruperto Aguirre y Francisco Cumia, que ejercían en Pamplona, y Fermín Lecumberri, de Tafalla.

De Pamplona, además de los citados, también participaron en el congreso Fermín Lecumberri y Saturnino Martínez. Todos ellos habían formado parte de la Junta constituida en la ciudad con ocasión de la epidemia de cólera, presidida por Luis Martínez Ubago ${ }^{16}$ que, sin embargo, no consta que asistiera a la reunión de Tafalla.

\section{Sistemática del congreso}

Los organizadores, según sus propias palabras, tomaron como modelo el "empleado por la Academia de Medicina de París", pero "con adiciones y modificaciones que creímos importantes" (p. 8).

Se organizaron cinco sesiones, dos diarias, más la de inauguración y la de clausura. Cada sesión dio lugar a una conclusión que en algunos casos se tomó de forma mayoritaria, con votos particulares, lo cual nos ha facilitado la identificación de los puntos más discutidos.

Se propuso que las intervenciones de los ponentes duraran un máximo de $15 \mathrm{mi}$ nutos y las de las réplicas, no más de 10. Además, y sobre un mismo punto, sólo se admitía una intervención por congresista.

Los temas programados para las sesiones fueron los siguientes:

1. Diversos modos de importación y propagación del cólera, limitándose a aducir hechos bien probados de la práctica propia.

2. ¿El cólera es infeccioso, contagioso o tiene ambos modos de propagación, tomando estas palabras en el sentido puramente epidemiológico?

3. Hechos relativos a la duración del período de incubación en el individuo y en la localidad. Hechos y datos estadísticos sobre la diarrea llamada premonitoria y sobre los casos tan cuestionados apellidados fulminantes.

4. Patología y terapéutica del cólera.

5 . Higiene y profilaxis individual y urbana.

6. Asuntos profesionales relativos a epidemias. El médico ante las leyes sanitarias, en las Juntas de Sanidad, en sus relaciones con la administración municipal y en sus deberes y derechos con la sociedad en general y con su clientela" (p. 8).

Estos seis enunciados respondían a las preguntas del cuestionario que previamente se había enviado a los médicos. El congreso trató sólo de los cinco primeros temas porque los debates que suscitaron consumieron el tiempo de la reunión. Quedaron, por consiguiente sin abordar, las cuestiones profesionales.

Al término de las sesiones se nombró una comisión formada por Antonio Martín Ayuso, Ruperto Aguirre, Javier Yárnoz, Manuel Jimeno y Ricardo García para que redactaran una memoria del congreso, que fue publicada con el auspicio de la Diputa- 
ción de Navarra bajo el título: El Congreso Médico-Regional de Navarra en 1886: memoria científico-descriptiva por la Comisión nombrada al efecto (Pamplona: Imprenta Provincial, 1886).

En este artículo vamos a centrarnos el análisis de los cuatro aspectos que, a mi juicio, reflejan mejor la transmisión de los avances científicos entre los profesionales que asistieron al congreso: la propagación fluvial del cólera, el recurso a la estadística, las teorías etiopatogénicas del cólera y el debate sobre las medidas de higiene de orden público.

\section{RESULTADOS}

\section{La propagación fluvial del cólera}

La primera sesión trató acerca de los Diversos modos de importación y propagación del cólera. La ponencia fue presentada por el médico y cirujano de Pamplona, Manuel Ferrer. Tras el debate correspondiente se llegó a la conclusión de que "El cólera tiene su exclusivo origen en ciertas regiones asiáticas; su espontaneidad fuera de aquellas regiones no es probable. De allí es importado a los demás países, por los barcos, por el hombre y por algunos objetos de su uso, propagándose en la dirección de las comunicaciones humanas" (p. 22).

El punto que más controversia suscitó esta ponencia fue el relativo a la propagación del cólera por las aguas fluviales. John Snow había demostrado en Londres, en 1854, la influencia del abastecimiento de aguas en la epidemia de cólera. Sin embargo, las medidas adoptadas contra la epidemia por la Junta de Sanidad demuestran que había serias dudas sobre el papel de los ríos en la propagación de la enfermedad. Una de las razones de la incertidumbre era que Pamplona, ciudad atravesada por los ríos Arga y Sadar, había tenido una afectación baja en la epidemia de 1885 .

El médico de Falces, Segundo Ortega, aseguró en la sesión que la llegada del cólera a su localidad se produjo a través del río Arga, ya que en sus aguas se habían lavado las ropas de un soldado invadido en Miranda, pueblo situado aguas arriba (p. 36).

El congreso reconoce que "lo más probable" es que las aguas fluviales "puedan servir de vehículo del germen", pero que para que el cólera fuera patógeno hacía falta "una preparación telúrica", es decir, que su eclosión dependía de las condiciones ambientales y de la composición de la tierra y del agua.

Apoyaban esta postura los informes de los médicos de Estella (doctor Iribas) y de Mendigorría (doctor Megía), quienes afirmaron que "en algunas localidades ribereñas bastante azotadas, en cuyos estragos con un examen superficial pudiera creerse hubiesen tenido influencia las aguas de los ríos, no se bebía el agua de estos aún desde antes de la aparición de la epidemia" (p. 39).

En efecto, la relación entre la propagación de la epidemia y la contaminación de las cuencas de los ríos fue demostrada más adelante, en 1887, por el doctor Philip Hauser (1832-1925) ${ }^{17}$. Y, posteriormente, se ha explicado el bajo número de invadidos en Pamplona porque el agua de consumo de la ciudad procedía de un manantial (Subiza) no contaminado, independiente de los ríos que atraviesan la ciudad y que era transportada a través de un acueduc$\mathrm{to}^{3,5}$.

\section{El empleo de la estadística}

Debido a la actitud de los médicos, contamos con numerosos datos estadísticos de la epidemia de 1885 en Navarra, cosa que no ocurre con las invasiones coléricas anteriores. Algunos datos se anotaron durante la epidemia, mientras que otros se recopilaron meses después de que fuera erradicada. Todo lo cual explica que la Memoria del congreso navarro reconozca que, según la fuente, "algunas de estas cifras se diferencian bastante de las del Estado Oficial" (p. 84). Durante el congreso, los médicos se atuvieron, en general a los datos estadísticos de la Gaceta de Madrid ${ }^{18}$, ya que fueron lo que consideraron "más auténticos" (p. 58). 
Como hemos demostrado en un trabajo previo, la diferencia en las cifras de los registros se debe a errores y a los diferentes criterios en la cumplimentación de los impresos ${ }^{19}$. Además, las disparidades en las cifras de la epidemia era algo común, y también fueron descritas en las epidemias de cólera de otras localidades ${ }^{1}$ como Santander $^{20} \mathrm{o}$ Valladolid ${ }^{21}$.

La abundancia de datos en Navarra permite conocer la intensidad diaria de fallecimientos y la mortalidad de cada población, por sexo y profesión. Así como su relación con el abastecimiento de aguas y las actuaciones sanitarias. Resumiendo, en Tudela se declararon el $46,9 \%$ del total de invadidos en Navarra (6.048 invasiones: 2.481 en hombres y 3.567 en mujeres). En orden de importancia sigue el Partido judicial de Estella (2.833 invadidos, $21,9 \%$ ) y el de Tafalla (2.568 invadidos, 19,9\%) y con menos intensidad Aoiz (775 invadidos, 6\%) y Pamplona (673 invadidos, 5,2\%).

La Memoria refleja que la mayor mortalidad se produjo en la ribera del Ebro: Fustiñana fue el municipio más afectado, "con 10,83\% de mortalidad, Buñuel 8,41\%, Cabanillas 8,04\%, Cortes 7,18\%, Murchante $7,18 \%$, Valtierra 6,95\%". Mientras que "en los distritos de Aoiz y Pamplona en la mayor parte de los pueblos no llega la mortalidad a $0^{\prime} 70 \%$ (p. 72). Durante el congreso, los médicos compararon los datos de $\mathrm{Na}$ varra con los del resto de España y con las cifras de otros países europeos.

El cambio de mentalidad que aquí se detecta es que los médicos se planteen "aducir hechos bien probados de la práctica propia" y reconozcan que "las epidemias tienen fisonomía propia, no sólo individuales, por lo que hay que recoger gran número de observaciones, analizarlas y compararlas sistemáticamente" (p. 8). Por lo que bien podemos concluir que el esfuerzo por medir, a través de cuestionarios y encuestas, el alcance de la epidemia es un eco del movimiento más general y difundido a través de los congresos internacionales de higiene. Además, poco a poco, se desarrolló cierta unificación en los criterios y en la terminología del análisis estadístico.

\section{La etiopatogenia del cólera}

La sesión segunda del congreso se dedicó a la cuestión: ¿El cólera es infeccioso, contagioso o participa de ambos modos de propagación? Y la cuarta a la Patología y terapéutica del cólera. Ambas sesiones dieron lugar a discusiones "muy animadas". La sesión segunda fue la que contó con un mayor número de intervenciones del congreso que correspondieron a Martín Ayuso, Cabezudo, Moneo, Ortega, Vieta, Aguirre, Pereda, Serrano, Contreras, Ferrer, Mejía, Ortiz, Fernández, Yárnoz, Andorra, Martínez y Jimeno. Y la conclusión a la que se llegó fue aprobada por 25 votos contra 1, mientras que la cuarta sesión, fue resumida por el doctor Espina, quien consiguió que fuera aceptada por unanimidad.

El desarrollo de las dos sesiones muestra la actitud de los médicos ante la incipiente microbiología. En la primera sesión del congreso se "acordó por aclamación dirigir al eminente experimentador, $\mathrm{Mr}$. Pasteur, un mensaje de felicitación por sus últimos e importantísimos trabajos sobre la curación de la rabia, al que contestó manifestando su reconocimiento" (p. 18). Además, los congresistas conocían las acaloradas discusiones que siguieron al descubrimiento por Robert Koch del Bacillus vírgula, en 1883, y el reflejo de aquella polémica entre los médicos españoles ${ }^{22}$. Así lo demuestra, por ejemplo, la referencia a "la discusión sobre el informe relativo a la epidemia de cólera en Francia en 1884 por la comisión compuesta por Bergeron, Besnierm Fauvel, Guéncan de Mussy-Brouardel, Legonert, Pasteur, Rochard, y en la que actuó Marey como ponente" (p. 96).

El congreso de Tafalla admitió sin problema que el agente del cólera era el "microbio de Koch" (p. 96). Sin embargo, las actas reflejan las dudas que existían en el ambiente científico-profesional. Se acepta un descubrimiento, pero no atribuyen al bacilo la etiología única de la enfermedad. El prefacio de la memoria expresa: "El estudio paciente y sistemático de las epidemias es medio tan importante por lo menos, como las investigaciones microbiológicas, de llegar a conocer la etiología y patoge- 
nia del cólera, a cuyo conocimiento ha de seguir de cerca el de su profilaxis, problemas que tanto interesan a la humanidad" (p. 97).

Al final de los años 1880, para muchos, el origen del cólera estaba en relación con las emanaciones de miasmas producidas por los cuerpos en descomposición de los cadáveres de coléricos. Y entre los médicos navarros, de igual modo que en sus coetáneos, de otros lugares, continúan las conexiones entre el cólera y los fenómenos atmosféricos, como las tormentas: "En cuanto a las tormentas, en Allo, previo a la presentación de los casos hubo una gran tormenta con vientos huracanados y en Estella se cita que durante el apogeo cayó "lluvia fuerte".

La doctrina miasmática evolucionó con la formulación de la doctrina telúrica por Pettenkoffer, doctrina que, en España fue introducida, entre otros, por el médico húngaro $\mathrm{Ph}$. Hauser ${ }^{17,23,24}$. De ahí el interés de los médicos navarros en el congreso por el examen comparativo de las tierras de unas localidades con otras. Esas diferencias podían explicar "que las invasiones coléricas revistieron en unas el carácter de la más ligera infección telúrica y en las otras el de la más terrible intoxicación, producida por el más mortífero de los venenos" (p. 118).

Por lo tanto, continúan vigentes los tres elementos con los que Nicasio Landa explicaba, en 1855, la etiología de aquella epidemia colérica: el "agente" colérico, compatible con la hipótesis microbiana; el ambiente social derivados del hacinamiento, la pobreza; y el ambiente telúrico o la composición geológica de los terrenos ${ }^{11,25}$.

Esta complejidad y el solapamiento de doctrinas se pone de manifiesto cuando el congreso de Tafalla define los términos de infección y contagio, como algo diferenciado:

"Infección debe denominarse la acción morbosa sobre nuestro organismo de un agente orgánico cuyo poder morboso no es puramente físico o químico. Si es de origen telúrico es un miasma; (concepto moderno; antiguamente el concepto de miasma era sinónimo del de emanación gaseosa); si es de origen animal es un virus".

$\mathrm{Y}$ entienden que "Contagio, en el concepto hoy corriente en Epidemiología, es la propagación de un agente que solo se cría en los humores orgánicos. Ambas denominaciones se refieren a un mismo concepto, pero el de contagio es más restringido que el de infección" (las cursivas son del original, p. 98).

En resumen, el cólera en su aspecto etiológico, se enmarcaría entre las enfermedades por "causas vivas": "el cólera es producido por un germen morboso telúrico, y es, por tanto, exclusivamente infeccioso".

Al inicio de la epidemia, los médicos utilizaron diversas denominaciones para el cuadro colérico. Así aparecen descritos casos de "cólicos sospechosos", de "catarro intestinal coleriforme", de "cólico coleriforme", de "enteritis coleriforme", de "cólera nostra"...; tras esa plural denominación probablemente existía el miedo a declarar que se trataba de una nueva epidemia colérica ${ }^{19}$.

Respecto a los tratamientos empleados, el congreso de Tafalla reconocía que las drogas y las medidas terapéuticas que prescribían iban dirigidas tan sólo a combatir los síntomas. La escalada terapéutica que había sido practicada era: "la anexosmótica (es decir, la utilización de antidiarreicos), en el primer período; la narcótica en el segundo; y la excitante y antiséptica en el tercero". Según el análisis de los médicos, las cifras de mortalidad no demostraron que hubiera un tratamiento más eficaz que otro, ya que "con tan diferentes tratamientos se han obtenido casi iguales resultados" (p. 125).

El congreso estudió también si haber padecido el cólera ofrecía inmunidad y protegía de nuevos contagios. En este aspecto, los médicos navarros manifiestan su coincidencia con la Academia de Medicina de París y concluyen: "no creemos muy aventurado afirmar que, al menos las formas más leves del cólera (colerina) no confieren inmunidad alguna próxima ni remota" (p. 78). 
A lo largo del congreso, los médicos citan en varias ocasiones a Jaime Ferrán y Clúa (1852-1929), pero sólo marginalmente hacen referencia a la acre polémica desarrollada en 1885 por la difusión de su vacuna anticolérica: "el Dr. Ferrán -se lee en la Memoria- excitaba poderosamente la atención pública con sus inoculaciones profilácticas y las reclamaciones de la prensa y de la opinión" (p. 43) ${ }^{1,22}$. El congreso no toma postura al respecto y de la controversia sólo le interesa destacar que los informes emitidos determinan que se trata de una verdadera epidemia de cólera.

Posiblemente la razón de esta actitud del congreso es que entre sus objetivos estaba el conseguir acuerdos en los temas tratados, no abrir disensiones. También pudo influir el poco tiempo del que dispusieron para la reunión; así como la presencia de Espina y Capo, representante de la Academia de Medicina de Madrid, institución que se había manifestado en contra de la vacuna.

Por otras fuentes sabemos que algunas localidades, como Tudela, solicitaron a Madrid autorización para que allí se practicara la vacunación, lo cual nunca se aprobó.

El tiempo ha mostrado que el vehemente debate sobre la vacuna de Ferrán influyó en la difusión de la doctrina bacteriológica en España ${ }^{26}$.

\section{A favor o en contra del aislamiento de las poblaciones}

La última sesión del congreso se dedicó a la Higiene y profilaxis individual y urbana. En Navarra, al igual que en el resto de las provincias, la organización sanitaria dependió de la Junta Provincial de Sanidad y de las Juntas Municipales. La Junta Provincial de Navarra indicó medidas de desinfección de viajeros, ropas y mercancías, así como la inspección médica de los saneamientos y alcantarillados de las poblaciones. Por ejemplo, en Pamplona, el doctor Landa, ante la inminente amenaza del cólera en 1884 recomendó "que debían adoptarse medidas enérgicas respecto al alcantarillado de la población porque es sumamente perjudicial" 27 .
En la reunión de Tafalla se llegó pronto a un acuerdo respecto a las medidas de higiene privada: "el congreso nada tiene que modificar ni añadir a la doctrina admitida en el estado actual de la ciencia, y aunque no reconoce en ningún agente de los propuestos como profilácticos absoluta eficacia, recomienda, en tal concepto, la limonada clorhídrica y las sales de quinina, en virtud de que algunos hechos de experiencia recogidos durante la última epidemia, permiten suponer tengan acción beneficiosa" (p. 23).

También recomienda para desinfectar la ropa y otros efectos, la estufa seca y, en su defecto, el ácido sulfuroso, la inmersión en soluciones de bicloruro de mercurio o en agua salada hirviendo, durante una hora. Para las cloacas, letrinas y deyecciones, el bicloruro de mercurio, el sulfato cúprico, el ferroso y el cloruro de cal, fueron las substancias aprobadas.

En cambio, "fue objeto de empeñado debate" la cuestión del aislamiento de las poblaciones como medio profiláctico, cuestión que hay que apreciar con algo de perspectiva. A lo largo del siglo XIX, el sistema cuarentenario fue cada vez más criticado. Se consideró ineficaz para detener el avance de las epidemias y se pusieron de relieve los efectos negativos que tenía ${ }^{28}$. El aislamiento producía desabastecimiento en los mercados, paralizaba las industrias y la vida económica en general, por lo que era seguido de hambre y pobreza. Además, a veces, se imponía con brutalidad.

Este rechazo adquirió carácter de acuerdo en la Conferencia Internacional sobre el cólera celebrada en Roma, en 1885. Allí se rechazaron los cordones y las cuarentenas terrestres con el único voto en contra de Turquía. Sin embargo, en España, estas medidas todavía estaban muy arraigadas, tanto entre algunos médicos, como en la sociedad. De hecho, el representante del gobierno español en la Conferencia de Roma tenía indicación de votar en contra de la supresión de la cuarentena, pero no lo hizo porque no llegó a tiempo a la votación ${ }^{24,29}$.

El miedo al contagio hizo que se mantuviera la Ley Orgánica de Sanidad de 1855 
que admitía que en "circunstancias especiales se puedan tomar medidas coercitivas". La realidad es que, en 1885, en España, el gobierno utilizó y recomendó los acordonamientos, los lazaretos y las cuarentenas interiores.

En cambio, el congreso de Tafalla, con 28 votos contra 2, aprobó la siguiente conclusión promovida por Nicasio Landa y Antonio Martín Ayuso: "si bien el aislamiento absoluto es medio seguro de preservar del cólera a una localidad, dicho aislamiento, como la experiencia ha demostrado una vez más en la última epidemia, es irrealizable y perjudicial, porque, resultando ineficaz para preservar del mal, es dispendioso, vejatorio y ruinoso para la agricultura, la industria y el comercio, y porque los pueblos dejan de invertir en su saneamiento, las cuantiosas sumas que malgastan en ilusoria incomunicación".

Insisten los médicos en que "los lazaretos y cuarentenas terrestres son contraproducentes". Y que "El médico, como consejero de la Administración en las Juntas de Sanidad no debe recomendar el aislamiento de una población" (p. 23).

Hay que señalar que esta opinión mayoritaria tuvo en contra el voto particular del doctor Yárnoz, a la sazón representante del Ayuntamiento de Pamplona. Y además, hemos comprobado que el debate sobre este asunto no se zanjó en Tafalla, pese al aparente acuerdo de la opinión médica. Cuando en 1890 llegan noticias de la siguiente onda expansiva de cólera, se vuelve a discutir acaloradamente en la Junta Provincial de Sanidad de Navarra la recomendación del aislamiento de las poblaciones. El doctor Revestido y otros facultativos de la junta recomendaban las medidas más rigurosas y absolutas, frente a Nicasio Landa, que sólo fue apoyado por los miembros no médicos de la Junta. En la votación ganaron ajustadamente ( 8 a 6 ) los partidarios de Landa ${ }^{30}$. Y un debate similar se plantea en la Junta Provincial de Sanidad celebrada el 30 de agosto de $1892^{31}$. Afortunadamente, el cólera no invadió Navarra en estas ocasiones.

\section{CONCLUSIONES}

La reunión científico médica de Tafalla fue una iniciativa nueva. Hemos podido observar la transferencia de ideas de los congresos internacionales y de otras instituciones como la Academia de Medicina de París, en la organización de una reunión médica de carácter regional y formada mayoritariamente por médicos rurales.

1. Esta influencia fue mediada por personalidades que habían participado en foros más amplios, en este caso, Nicasio Landa y Antonio Espina y Capo. Y se manifiesta en el esfuerzo por unificar los métodos de análisis y la terminología en que se expresan los contenidos científico-médicos. El interés por medir estadísticamente y a través de las encuestas el alcance de la epidemia es eco de un movimiento más general. Como señala Rasmussen, en las reuniones internacionales de la época se observa un saber "monolítico" y un proceso en el que se pasa de una ciencia individual a una ciencia colectiva. Se incorporan nuevas prácticas, fundadas en la comunicación y la colaboración de los profesionales ${ }^{32}$.

2. Al mismo tiempo, observamos diferencias en las concepciones de los médicos. Unos continuistas con las teorías y prácticas anteriores, otros novedosos y basados en una nueva mentalidad. En esos momentos todavía no había en el mundo científico una visión unitaria del paradigma microbiológico. Los cuestionarios elaborados por los médicos navarros para el estudio de la epidemia de cólera abarcan múltiples variables (tipos de agua, composición de la tierra, fenómenos atmosféricos, cuestiones sociales y sanitarias, etc.), lo cual ejemplifica el modo de proceder en el análisis de un problema de la salud pública para el que no existía una explicación causal satisfactoria.

3. Se pone de manifiesto la circulación de las prácticas higiénicas y la cons- 
trucción de un modelo de higiene pública común en la Europa de finales del siglo XIX, lo cual, hemos podido comprobarlo, no se circunscribe a las reuniones internacionales.

4. Desde un punto de vista profesional, la reunión demuestra el impulso del asociacionismo que fraguará en la constitución de los Colegios Oficiales de médicos. El congreso de Tafalla manifiesta el voluntarismo de los médicos en las emergencias y para establecer instrumentos de trabajo comunes. Pero también, pone de relieve la profesionalización de las tareas higiénicas y el entramado sanitario-social que de él se derivó.

\section{Agradecimientos \\ Deseo manifestar mi agradecimiento a la PhoenixTN, European Thematic Network on Health and Social Welfare Policy y a los profesores de Historia de la Medicina del Departamento de Humanidades Biomédi- cas de la Universidad de Navarra por sus sugerencias y consejos en esta investiga- ción.}

\section{BIBLIOGRAFÍA}

1. Fernández Sanz JJ. 1885: el año de la vacunación Ferrán: trasfondo político, médico, sociodemográfico y económico de una epidemia. Madrid: Fundación Ramón Areces, 1990.

2. Carnicero Giménez de Azcárate J. Félix Aramendía (1856-1894) y la patología y clínica médicas. Pamplona, 2007, pp. 111-156.

3. Martínez Lacabe E. Violencia y muerte en Navarra: guerras, epidemias y escasez de subsistencia en el siglo XIX. Pamplona: Universidad Pública de Navarra, 2004.

4. Orta Rubio E. Centenario de una crisis demográfica: el cólera de 1885 en Navarra. Príncipe de Viana 1986; XLVII.I (Anejo 4): 79-91.

5. Anaut Bravo S. Siguiendo las huellas del último brote de cólera en Pamplona (1885). Estudios de Ciencias Sociales. Pamplona: UNED, 1985: 150-161.

6. Campo Vidondo JM, Gastón Aguas JM. El cólera en Navarra. Peralta, un ejemplo. Tafalla: Altaffaila Kultur Taldea, 98, 1993.
7. El Congreso Médico-Regional de Navarra en 1886: memoria científico-descriptiva por la Comisión nombrada al efecto. Pamplona: Imprenta Provincial, 1886.

8. VIÑES JJ. El doctor Nicasio Landa, médico y escritor: Pamplona 1830-1891. Pamplona: Gobierno de Navarra, Departamento de Educación y Cultura, 2001.

9. Diestro y Vega J, Martín Ayuso A. Deontología. Deberes generales del médico en el ejercicio de la profesión y relaciones de los médicos entre si. El Siglo Médico, 2482 (21 de julio de 1901): 483.

10. Anaut Bravo S. Luces y sombras de una ciudad: los límites del reformismo social y del higienismo en Pamplona. Pamplona: Universidad Pública de Navarra, 2001, pp. 33-38.

11. VIÑEs JJ. El Dr. D. Nicasio Landa, médico oficial de epidemias en la de cólera de 18541855. An Sist Sanit Navar 2000; 23: 85-107.

12. Actas Junta Sanidad de Navarra, $85-88$, junio 1885. En: Viñes JJ. La sanidad española en el siglo XIX a través de la Junta Provincial de Sanidad de Navarra (1870-1902). Pamplona: Gobierno de Navarra, Departamento de Salud, 2006, pp. 551-560.

13. Archivo del Senado, HIS-0153-07

14. Renaudet I. La contribution du Dr Antonio Espina y Capo à la Revista de Medicina y Cirugía prácticas: un combat au service du progrès médical. El argonauta español, 2, 2005.

15. Ulecia y Cardona J. Tratamiento del cólera morbo-asiático: exposición de los principales métodos y fórmulas empleadas contra esta terrible enfermedad por reputados profesores nacionales y extranjeros. Madrid: Administración de la Revista de Medicina y Cirugía Prácticas, 1885.

16. VIÑES JJ. La sanidad española en el siglo XIX a través de la Junta Provincial de Sanidad de Navarra (1870-1902). Pamplona: Gobierno de Navarra, Departamento de Salud, 2006, p. 251.

17. HAUSER Ph. Atlas epidemiográfico del cólera de 1885 en España con diez y ocho mapas representando la marcha invasora de la epidemia en la península. Madrid: Imp y Fund. de Manuel Tello, 1887.

18. Cólera morbo asiático en España durante el año 1885. Gaceta Sanitaria 7 de abril de 1886, Boletín Estadístico Sanitario Demográfico. Madrid: Establecimiento Tipográfico Sucesores de Rivadeneyra, 1887, Apéndice.

19. SARRASQueta P, León P. Análisis de los registros oficiales de la epidemia de cólera de 1885 en 
Tudela. En: Campos R, Montiel L, Huertas R (coord.) Medicina, Ideología e Historia en España (Siglos XVI-XXI). Madrid: CSIC, 2007, pp. 241-251.

20. Maestre SÁnchez A. El cólera en Santander. La epidemia del año 1834. Santander: Ayuntamiento de Santander, 1985, p. 329.

21. LloRente de la Fuente A. La epidemia de cólera de 1885 en Valladolid. Salamanca: Universidad de Valladolid, 1993, pp. 59-60.

22. Faus Sevilla P. Epidemias y sociedad en la España del siglo XIX. El cólera de 1885 en Valencia y la vacunación de Ferrán. En: López Piñero JM, García Ballester L, Faus Sevilla P. Medicina y sociedad en la España del siglo XIX. Madrid: Sociedad de Estudios y Publicaciones, 1964, pp. 287-486 (307-313).

23. Carrillo JL. (ed.), Entre Sevilla y Madrid: estudios sobre Hauser y su entorno. Sevilla: Servicio de Publicaciones de la Universidad, 1999.

24. RodRÍGueZ OCAÑA E. Confort, ornamentation, hygiène. Modernisation urbaine et hygiénisme dans l'Espagne du XIX ${ }^{e}$ siècle. En: Bourdelais P. dir. Les hygiénistes: enjeux, modèles et pratiques (XVIIIe-XXe siècles). Paris: Belin, 2001, pp. 297-318 (311-313).

25. LANDA N. Memoria sobre la relación que ha existido entre la constitución geológica del terreno y el desarrollo del Cólera-morbo en España, que presentó a la Real Academia de Medicina de Madrid en 1861.
26. Rodríguez Ocaña E. Por la salud de las naciones: higiene, microbiología y medicina social. Torrejón de Ardoz: Akal, 1992.

27. Acta Junta Sanidad de Navarra, 75, junio 1884. En: Viñes JJ. La sanidad española en el siglo XIX a través de la Junta Provincial de Sanidad de Navarra (1870-1902). Pamplona: Gobierno de Navarra, Departamento de Salud, 2006, p. 531-534.

28. Angolotti E. Las invasiones del cólera en España. Contagionistas y anticontagionistas. Rev San Hig Pub 1975; 49: 1077-1164.

29. TaBOAdA de la Riva M. Sanidad Internacional. Discurso en la Real Academia de Medicina en Madrid, 1897.

30. Acta Junta Sanidad de Navarra, 111, julio 1890. En: Viñes JJ. La sanidad española en el siglo XIX a través de la Junta Provincial de Sanidad de Navarra (1870-1902). Pamplona: Gobierno de Navarra, Departamento de Salud, 2006, pp. 591-592.

31. Acta Junta Sanidad de Navarra, 123, agosto 1892. En: Viñes JJ. La sanidad española en el siglo XIX a través de la Junta Provincial de Sanidad de Navarra (1870-1902). Pamplona: Gobierno de Navarra, Departamento de Salud, 2006, pp. 612-613.

32. RASMUSSEN A. L'hygiène en congrès (1852-1912): circulation et configurations. internationales. En: Bourdelais P. dir., Les hygiénistes: enjeux, modèles et pratiques (XVIIIe-XXe siècles). $\mathrm{Pa}$ ris: Belin, 2001, 213-239 (219, 233, 235). 
